\title{
COMPARISON OF FIELD AND AIRBORNE LASER SCANNING BASED CROWN COVER ESTIMATES ACROSS LAND COVER TYPES IN KENYA
}

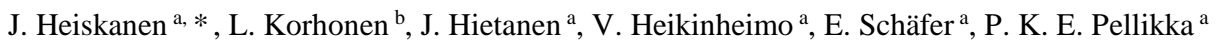 \\ ${ }^{a}$ Department of Geosciences and Geography, University of Helsinki, P.O. Box 68, FI-00014, Helsinki, Finland - (janne.heiskanen, \\ jesse.hietanen, vuokko.heikinheimo, elisa.schafer, petri.pellikka)@ helsinki.fi \\ ${ }^{\mathrm{b}}$ Department of Forest Sciences, University of Helsinki, P.O. Box 27, FI-00014, Helsinki, Finland - lauri.z.korhonen@ helsinki.fi
}

KEY WORDS: Canopy cover, Crown relascope, Hemispherical photography, LiDAR

\begin{abstract}
:
Tree crown cover (CC) provides means for the continuous land cover characterization of complex tropical landscapes with multiple land uses and variable degrees of degradation. It is also a key parameter in the international forest definitions that are basis for monitoring global forest cover changes. Recently, airborne laser scanning (ALS) has emerged as a practical method for accurate CC mapping, but ALS derived CC estimates have rarely been assessed with field data in the tropics. Here, our objective was to compare the various field and ALS based CC estimates across multiple land cover types in the Taita Hills, Kenya. The field data was measured from a total of 178 sample plots ( 0.1 ha) in 2013 and 2014. The most accurate field measurement method, line intersect sampling using Cajanus tube, was used in 37 plots. Other methods included CC estimate based on the tree inventory data (144 plots), crown relascope (43 plots) and hemispherical photography (30 plots). Three ALS data sets, including two scanners and flying heights, were acquired concurrently with the field data collection. According to the results, the first echo cover index (FCI) from ALS data had good agreement with the most accurate field based CC estimates (RMSD $7.1 \%$ and $2.7 \%$ depending on the area and scan). The agreement with other field based methods was considerably worse. Furthermore, we observed that ALS cover indices were robust between the different scans in the overlapping area. In conclusion, our results suggest that ALS provides a reliable method for continuous CC mapping across tropical land cover types although dense shrub layer and tree-like herbaceous plants can cause overestimation of $\mathrm{CC}$.
\end{abstract}

\section{INTRODUCTION}

Tropical landscapes show often great variation in tree crown cover (CC) depending on the land cover type and land use. Typically, the moist tropical forests have closed and multilayered canopies whereas drier vegetation types such as savannah woodlands have low CC. In the natural vegetation types, CC can be altered by degradation due to various disturbances. Furthermore, the managed land cover types, such as croplands and agroforestry systems, can have relatively high $\mathrm{CC}$ in the tropics (Zomer et al., 2009).

$\mathrm{CC}$ is the single most important variable in the various definitions of forest, including the definitions of forest and other wooded land by Food and Agriculture Organization (FAO) of the United Nations (FAO, 2010). Cover of trees is also an elementary classifier in FAO Land Cover Classification System (LCCS) for natural and semi-natural vegetated areas (Di Gregorio, 2005). The monitoring of tropical forest area has gained increasing attention because it is needed for the implementation of climate change mitigation policies, such as United Nations collaborative initiative on Reducing Emissions from Deforestation and forest Degradation (REDD) in developing countries.

$\mathrm{CC}$ is defined as the proportion of ground covered by the vertical projection of tree crowns in percentage (Jennings et al., 1999; Korhonen et al., 2006; Gschwantner et al., 2009). Crown is defined by its outer perimeter and hence the small within crown gaps are considered to belong to the crown.
$\mathrm{CC}$ can be estimated in the field using vertical sighting tubes (Korhonen et al., 2006). The accurate measurement of CC is very time consuming, and thus several methods have been developed to decrease the measurement time. However, the alternative methods are usually biased and not necessarily applicable for complete range of CC variation. One method is to estimate $\mathrm{CC}$ based on the tree inventory data

Often CC estimate is needed for the sample plots with basic forest inventory data. If tree positions and crown diameters are available, it is possible to estimate $\mathrm{CC}$ based on these. However, the estimate of the crown area can be biased when assuming a circular shape. Hemispherical photography (HP) is commonly used method for estimating canopy gap fraction (GF) and leaf area index (LAI) (Jonckheere et al., 2004). If view zenith angle is restricted close to zenith, HP can provide a proxy of CC (1-GF). However, images observe within crown gaps and hence the $\mathrm{CC}$ is underestimated. The additional methods for CC estimation include crown relascope (Stenberg et al. 2008), which can be used for very rapid CC assessment in sparsely stocked areas. Hence, it could be a useful method for CC estimation in savannah woodlands and croplands in the tropics.

Field measurements are viable only at sample plot scale and remote sensing is needed for mapping. Airborne laser scanning (ALS) has become a standard source of high-resolution remote sensing data for mapping forest attributes. The laser pulses are capable of detecting gaps in forest canopies, and hence offer three-dimensional information on canopy structure and sub-

* Corresponding author 
canopy topography. In addition to being very useful for assessing forest attributes, such as tree height and aboveground biomass, ALS data has been shown to provide accurate CC estimates even without field calibration data (Korhonen et al., 2011). Several ALS cover indices have been proposed to estimate CC, GF and LAI from discrete return ALS data (Korhonen and Morsdorf, 2014). Basically, the indices differ in terms of considered return types (single, first-of-many, intermediate and last-of-many returns) and if they are strictly geometrical or take into account return intensity. In all the indices, a height threshold needs to be set to separate canopy and ground returns.

So far, the agreement of the field and ALS based CC estimates has been rarely assessed in the tropics. In this paper, our objective was to compare field based CC estimates (vertical sighting tube, tree inventory, crown relascope and HP) and ALS based CC estimates across multiple land cover types in the Taita Hills, Kenya.

\section{MATERIAL AND METHODS}

\subsection{Study area}

The Taita Hills are located in the northernmost part of the Eastern Arc Mountains of Kenya and Tanzania, and cover approximately $1000 \mathrm{~km}^{2}$ (Figure 1). The hills rise from the lowlands at 600-900 m a.s.l. elevation to approximately $2200 \mathrm{~m}$ a.s.l. The hills are intensively cultivated and much of the forested land has been cleared for agriculture (Pellikka et al., 2009). Some remaining fragments of the indigenous cloud forest are restricted to the highest altitudes. In addition to the indigenous forest patches, plantations of exotic tree species, including eucalyptus (mostly Eucalyptus saligna), pines (Pinus spp.), cypress (Cupressus lusitanica) and black wattle (Acacia mearnsii) were established in the hills between the 1950s and 1970s. Mixed stands of indigenous and exotic species are also common (Pellikka et al., 2013). In the lower altitudes, the landscape is characterized by cultivated areas, open woodlands, shrublands and thickets with relatively low CC. Drought resistant tree species, such as Commiphora spp. Acacia spp. and Albizia amara are typical across the lowlands. Also fruit trees, such as mango (Mangifera indica) and cashew (Anacardium occidentale) are grown in the area.

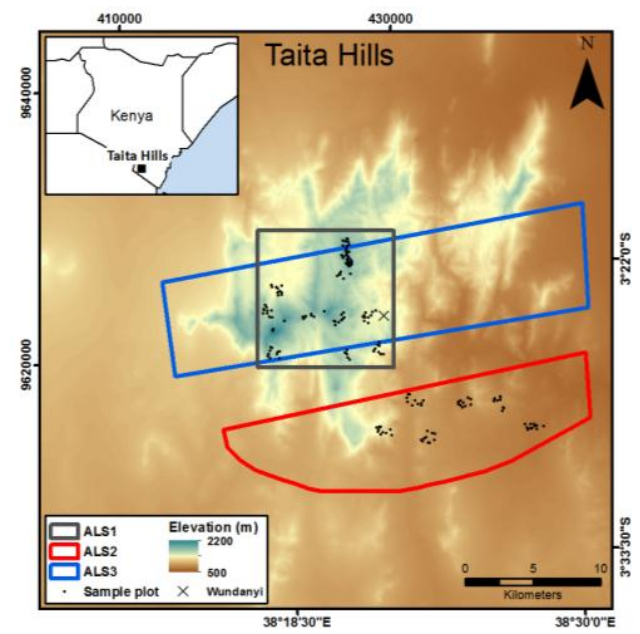

Figure 1. Location of the study area and sample plots, and extent of the three ALS data sets.

\subsection{Field estimates of $\mathrm{CC}$}

We used CC estimates from a total of 177 sample plots (Figure 1). All the data were collected in January-February 2013 and January-February 2014. The circular sample plots had a size of 0.1 ha (radius $=17.84 \mathrm{~m}$ ). The plot centres were positioned using a Trimble GeoXH GNSS receiver with an external antenna (Trimble Zephyr Model 2) mounted on a $2.6 \mathrm{~m}$ range pole. The positions were measured as long as we stayed in the plot. The differential correction was made using a GNSS base station located in the town of Wundanyi (Figure 1). The position of the base station was determined using Trimble RTX post-processing service (http://www.trimblertx.com).

The field data was combined from the several field campaigns in different parts of the study area and hence sampling strategy and methods of estimating CC varied between the plots. In 2013 measurements and in 2014 lowland measurements we selected sample plots randomly within $1 \mathrm{~km}^{2}$ clusters (ten plots in each cluster). In 2014, we sampled additional plots from forest areas in order to cover variation in aboveground biomass and tree species composition. This sampling was designed subjectively based on the canopy height model generated from 2013 ALS data and AisaEAGLE imaging spectroscopy data (Schäfer, 2014; Heiskanen et al., in press).

We used four methods for estimating $\mathrm{CC}$ in the field depending on the land cover type and tree density. The reference method, Cajanus tube with line intersect sampling (Korhonen et al., 2006), was used in 37 sample plots. CC measurement by Cajanus tube is time consuming and hence the number of plots was relatively small. However, the measurements covered all the land cover types and CC range in the study area. Cajanus tube is a vertical sighting tube, which provides an unbiased CC estimate if sample size is sufficient (Korhonen et al., 2006). In each of the 37 sample plots, we established nine transects (length 15.8-35.7 m) with four meter distance starting from the plot center point. In each transect, we recorded the starting and ending points of the crowns and identified the exact position of the crown edge by the Cajanus tube. Trees smaller than $3 \mathrm{~m}$ in height were not included in CC. Finally, we computed the distance that was covered by crowns and divided it by the total length of transects to estimate CC. These estimates are called hereafter $\mathrm{CC}_{\text {Cajanus. }}$

In 144 plots, CC was estimated based on tree inventory. The method was used in the plots outside forests (croplands, agroforestry, woodlands and shrublands), where it was feasible to measure position for each tree within the sample plot. The position (direction and distance from the plot center) and the diameter at breast height (DBH) were measured for all the trees having $\mathrm{DBH} \geq 10 \mathrm{~cm}$ by using a measurement tape and precision compass. Furthermore, crown diameter (CD) was measured by measurement tape in two perpendicular directions for all the trees in 2013 and for at least three trees in 2014 (minimum, median and maximum DBH). The mean CD was predicted for the trees missing $\mathrm{CD}$ measurement using linear regression. Finally, CC was computed as a percentage of the plot area covered by the tree crowns (overlapping crowns were counted only once). These estimates are called hereafter $\mathrm{CC}_{\text {trees. }}$.

Crown relascope was used in 43 sample plots in the lowlands, where tree densities are relatively low. Our crown relascope consisted of a $30 \mathrm{~cm}$ long and $3.2 \mathrm{~cm}$ wide plastic sheet and a string, the length of which was adjusted according to the crown basal area factor (CBAF) (Stenberg et al., 2008). Two CBAFs 
were tested: 100 and 200. When CBAF is 100 (200), each tallied tree corresponds to $1 \%(2 \%)$ increase in $\mathrm{CC}$. These estimates are called hereafter $\mathrm{CC}_{\mathrm{cr} 1}$ and $\mathrm{CC}_{\mathrm{cr} 2}$, respectively.

Furthermore, CC was estimated by HP for 30 plots. The majority of these plots were located in indigenous forests, but some plots were established in plantations (pine, cypress, eucalyptus and black wattle). We used Nikon D5000 camera and Sigma $4.5 \mathrm{~mm}$ 1:2.8 DC HSM fisheye lens. The lens was mounted on a tripod and levelled to the height of $1.3 \mathrm{~m}$. The number of camera positions per plot varied between five and eight. In the case of five positions, the images were taken from the center and $9 \mathrm{~m}$ to each cardinal direction. In the case of eight positions, the images were taken from $3 \mathrm{~m}$ and $9 \mathrm{~m}$ distance to each cardinal direction. In order to determine the exposure setting, we followed the histogram method of Beckschäfer et al. (2013). The image processing included the classification of images to the canopy and sky pixels using the blue band and automatic thresholding algorithm (Nobis and Hunziker, 2005). If the thresholding resulted in clear classification errors according to the visual assessment, we used either algorithm of Ridler and Calvard (1978) or determined threshold manually. After the classification, we computed CC for each image as a percentage of canopy pixels in the $0-15^{\circ}$ zenith angle range and averaged all the measurements in the plot for the plot-wise CC. These estimates are called hereafter $\mathrm{CC}_{\mathrm{HP}}$.

\subsection{ALS data}

We used three discrete return ALS data sets that covered different parts of the study area (Figure 1). The first scan (ALS1) was made 4-5 February 2013 and covered $10 \mathrm{~km} \times 10$ $\mathrm{km}$ area in the highest parts of the hills. The second scan (ALS2) was made 17 January 2014 and covered $150 \mathrm{~km}^{2}$ in the lowlands. The third scan (ALS3) was made 4 February 2014 and covered $330 \mathrm{~km}^{2}$, and partly overlapped with the first scan. In the first two scans, the sensor was Optech ALTM 3100 and in the third scan Leica ALS60. In the first scan, the flying height was relatively low and targeted pulse density relatively high in comparison to the 2014 scans. Further details are given in Table 1. The number of sample plots measured by each method and covered by the different ALS scans are summarized in Table 2.

All the ALS data sets were pre-processed by the data vendors (Topscan Gmbh, Ramani Geosystems) and delivered as georeferenced point clouds in UTM/WGS84 coordinate system with ellipsoidal heights. Ground returns in ALS1 and ALS2 data sets were filtered by the vendor using Terrascan software (Terrasolid Oy). Then, we used ground classified returns of ALS1 and ALS2 to produce digital elevation model (DEM) at 1 m cell size.

\subsection{ALS based CC estimates}

We extracted ALS data for the sample plots using several radii depending on the field measurement method. First, we extracted returns using $17.84 \mathrm{~m}$ radius corresponding to the area of 0.1 ha sample plot. Furthermore, in the crown relascope plots, we extracted returns for radius depending on the mean $\mathrm{CD}$ in the sample plot. The maximum radius (r) within which a tree crown is still tallied was computed as:

\begin{tabular}{|c|c|c|c|}
\hline Parameter & ALS1 & ALS2 & ALS3 \\
\hline Date & $\begin{array}{c}4-5 \mathrm{Feb} \\
2013\end{array}$ & $\begin{array}{l}17 \text { Jan } \\
2014\end{array}$ & $\begin{array}{l}4 \mathrm{Feb} \\
2014\end{array}$ \\
\hline Sensor & $\begin{array}{c}\text { Optech } \\
\text { ALTM } \\
3100\end{array}$ & $\begin{array}{c}\text { Optech } \\
\text { ALTM } \\
3100\end{array}$ & $\begin{array}{l}\text { Leica } \\
\text { ALS60 }\end{array}$ \\
\hline Mean range (m) & 760 & 1240 & 1460 \\
\hline Pulse rate $(\mathrm{kHz})$ & 100 & 70 & 58 \\
\hline Scan rate $(\mathrm{Hz})$ & 36 & 37 & 66 \\
\hline Scan angle $\left(^{\circ}\right)$ & \pm 16 & \pm 18 & \pm 16 \\
\hline $\begin{array}{l}\text { Pulse density } \\
\text { (pulses } \mathrm{m}^{-2} \text { ) }\end{array}$ & 9.6 & 2.9 & 3.0 \\
\hline $\begin{array}{l}\text { Return density } \\
\left(\text { returns } \mathrm{m}^{-2} \text { ) }\right.\end{array}$ & 11.4 & 3.3 & 3.4 \\
\hline $\begin{array}{l}\text { Beam divergence at } \\
1 / \mathrm{e}^{2}(\mathrm{mrad})\end{array}$ & 0.3 & 0.3 & 0.22 \\
\hline $\begin{array}{l}\text { Footprint diameter } \\
(\mathrm{cm})\end{array}$ & 23 & 37 & 32 \\
\hline
\end{tabular}

Table 1. Survey and sensor specifications for 2013 and 2014 scans. All sensors recorded a maximum of four returns per pulse.

\begin{tabular}{|l|c|c|c|c|}
\hline Method & ALS1 & ALS2 & ALS3 & Total \\
\hline Cajanus tube & 23 & 14 & 17 & 37 \\
Tree inventory & 83 & 61 & 66 & 144 \\
Crown relascope & & 43 & & 43 \\
HP & 30 & & 21 & 30 \\
\hline
\end{tabular}

Table 2. The number of sample plots measured by the different method and covered by different ALS scans.

$$
\mathrm{r}=\frac{50 \mathrm{CD}}{\sqrt{\mathrm{CBAF}}}
$$

where $\quad \mathrm{CD}=$ mean $\mathrm{CD}$ in the sample plot

$\mathrm{CBAF}=$ crown basal area factor $(100$ or 200$)$

Finally, we extracted returns also for larger fixed radii of $25 \mathrm{~m}$ in the plots measured by HP because of the non-zero view zenith angle.

When extracting ALS data for the sample plots, we also normalized return heights to the heights from the ground level by using DEM. Furthermore, as some plots were covered by several flight lines, we removed overlap between the adjacent flight lines based on minimum scan angle using lasoverage tool in LAStools software (rapidlasso $\mathrm{GmbH}$ ). This was done in order to minimize bias in the ALS based CC estimates due to the scan angle (Korhonen et al., 2011).

Then, we computed two ALS cover indices for the sample plots. First return cover index (FCI) (e.g., Solberg et al., 2006) has been found to be a good proxy of $\mathrm{CC}$ and relatively robust index between sensors and scans (Korhonen et al., 2011; Korhonen and Morsdorf, 2014). However, indices that incorporate intermediate and last returns, such as all return cover index (ACI) (e.g., Morsdorf et al., 2006) have been shown to provide better estimates of canopy GF, because they include information concerning both between crown and within crown canopy gaps (Korhonen et al., 2011). FCI and ACI were computed as: 


$$
\begin{gathered}
\mathrm{FCI}=\frac{\sum \text { Single }_{\text {canopy }}+\sum \text { First }_{\text {canopy }}}{\sum \text { Single }_{\text {all }}+\sum \text { First }_{\text {all }}} \times 100 \\
\mathrm{ACI}=\frac{\sum \text { All }_{\text {canopy }}}{\sum \text { All }} \times 100
\end{gathered}
$$

where $\quad$ Single canopy $=$ single return from canopy

Firstcanopy $=$ first return from canopy

Singleall $=$ any single return

Firstall $=$ any first return

$\mathrm{All}_{\text {canopy }}=$ any return from canopy

All $=$ any return (i.e. single, first, intermediate of last)

In the computation of ALS cover indices, canopy refers to the returns above a given height threshold that separates canopy returns from the understory and ground returns. Here, we computed indices using height thresholds of 3,4 and $5 \mathrm{~m}$.

\subsection{Analysis}

The best agreement with the field and ALS based CC (i.e. radii and height thresholds) was searched for each field measurement method. The agreement between the $\mathrm{CC}$ estimates was assessed using root mean square difference (RMSD) and average difference $(\mathrm{AD})$ :

$$
\begin{aligned}
\text { RMSD } & =\sqrt{\frac{\sum_{i=1}^{n}\left(y_{i}-\hat{y}_{i}\right)^{2}}{n}} \\
\mathrm{AD} & =\frac{\sum_{\mathrm{i}=1}^{\mathrm{n}}\left(y_{\mathrm{i}}-\hat{y}_{\mathrm{i}}\right)}{\mathrm{n}}
\end{aligned}
$$

where $\quad y_{\mathrm{i}}=$ field based CC estimate

$\hat{y}_{\mathrm{i}}=$ ALS based CC estimate

\section{RESULTS}

First, we compared $\mathrm{CC}_{\text {Cajanus }}$ and cover indices from ALS2 and ALS3 scans. ALS1 was not considered in this comparison as it was acquired in 2013 and there was one year difference with regard to the field measurements made in 2014. Furthermore, ALS covers approximately the same plots as ALS3 scan (Figure 1). CC Cajanus showed good agreement with FCI and AD were small (Figure 2a, Table 3). In the indigenous forest plots, $\mathrm{CC}_{\text {Cajanus }}$ was $100 \%$ or close to it, which describes the closed and multi-layered canopies in those forests. The optimal height threshold to separate canopy returns was different between the areas and scans. In the lowland areas (ALS2), $3 \mathrm{~m}$ height threshold provided the best agreement but in the hills $5 \mathrm{~m}$ was the best (ALS3). FCI provided better agreement with $\mathrm{CC}_{\text {Cajanus }}$ than $\mathrm{ACI}$, which underestimated $\mathrm{CC}_{\text {Cajanus }}$ in the plots of high canopy density where multiple returns were produced (Figure 2b, Table 3).
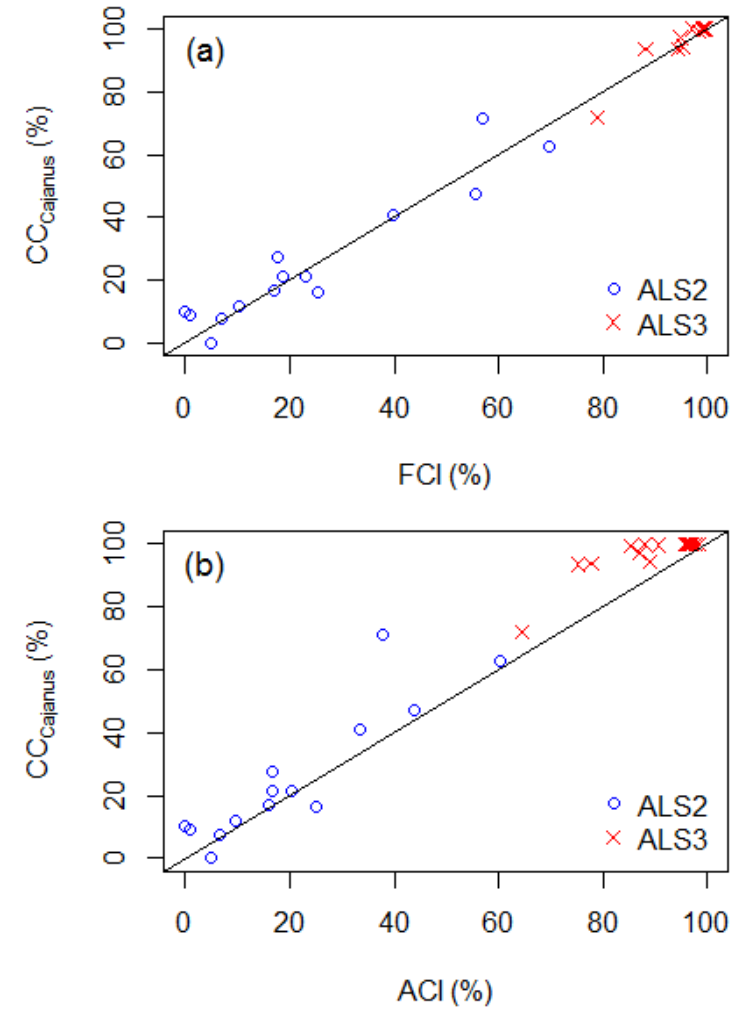

Figure 2. (a) FCI and (b) ACI against $\mathrm{CC}_{\text {Cajanus. }}$

\begin{tabular}{|c|c|c|c|c|}
\hline Scan & Index & HT & RMSD & AD \\
\hline ALS2 & FCI & $3 \mathrm{~m}$ & $7.1 \%$ & $1.3 \%$ \\
ALS2 & ACI & $3 \mathrm{~m}$ & $10.8 \%$ & $5.2 \%$ \\
ALS3 & FCI & $5 \mathrm{~m}$ & $2.7 \%$ & $0.1 \%$ \\
ALS3 & ACI & $3 \mathrm{~m}$ & $6.4 \%$ & $4.6 \%$ \\
\hline
\end{tabular}

Table 3. Summary of the comparison between CCCajanus, and ALS cover indices. HT $=$ height threshold for separating canopy and ground returns.

Next, we compared $\mathrm{CC}_{\text {trees }}$ and FCI from ALS1 and ALS2 scans, which corresponded to the years when tree inventories were made (Figure 3). Only FCI was tested because it showed the best agreement with $\mathrm{CC}_{\text {Cajanus, }}$ which we considered the most accurate method for $\mathrm{CC}$ estimation. In general, $\mathrm{CC}_{\text {trees }}$ had good agreement with FCI until 20\%. However, the values larger than $20 \%$ were underestimated in $\mathrm{CC}_{\text {trees }}$ and $\mathrm{AD}$ were negative. The height threshold of $5 \mathrm{~m}$ was the best for ALS1 (hills) and $4 \mathrm{~m}$ for ALS2 (lowlands).

Next, we compared crown relascope measurements and FCI from ALS2 because those measurements were available only from the lowland area. $\mathrm{CC}_{\mathrm{cr} 1}$ and $\mathrm{CC}_{\mathrm{cr} 2}$ rarely exceeded $20 \%$ although FCI values were greater than that (Figure 4). The agreement was somewhat better for $\mathrm{CC}_{\mathrm{cr} 2}$. The mean $\mathrm{CD}$ had a range of 3.5-14.0 $\mathrm{m}$ (mean $7.0 \mathrm{~m}$ ). Furthermore, the radii for $\mathrm{CC}_{\mathrm{cr} 1}$ had a range of $17.5-70.2 \mathrm{~m}$ (mean $34.8 \mathrm{~m}$ ) and $\mathrm{CC}_{\mathrm{cr} 2}$ 12.4-49.6 m (mean $24.6 \mathrm{~m}$ ). The height threshold of $3 \mathrm{~m}$ was used as it gave the best agreement between $\mathrm{CC}_{\text {Cajanus }}$ and FCI in this area (Table 3). However, we noted that increasing the height threshold from $3 \mathrm{~m}$ to $5 \mathrm{~m}$ decreased RMSD and AD but small CC were typically underestimated by FCI. 

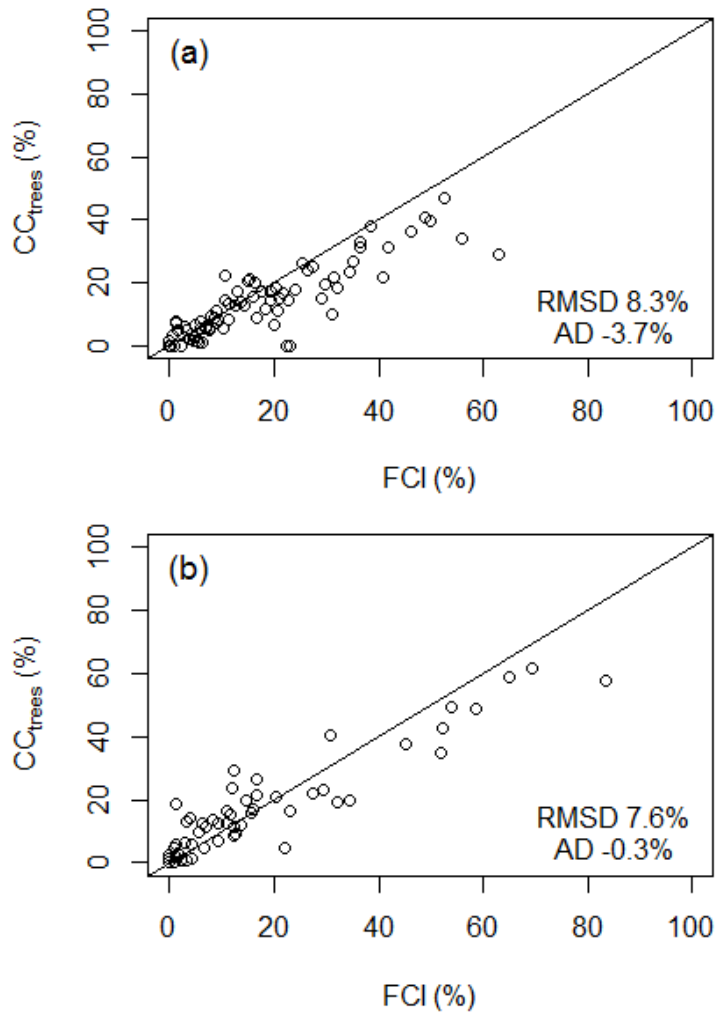

Figure 3. FCI from (a) ALS1 (5 m height threshold) and (b) ALS2 (4 m height threshold) against $\mathrm{CC}_{\text {trees }}$.
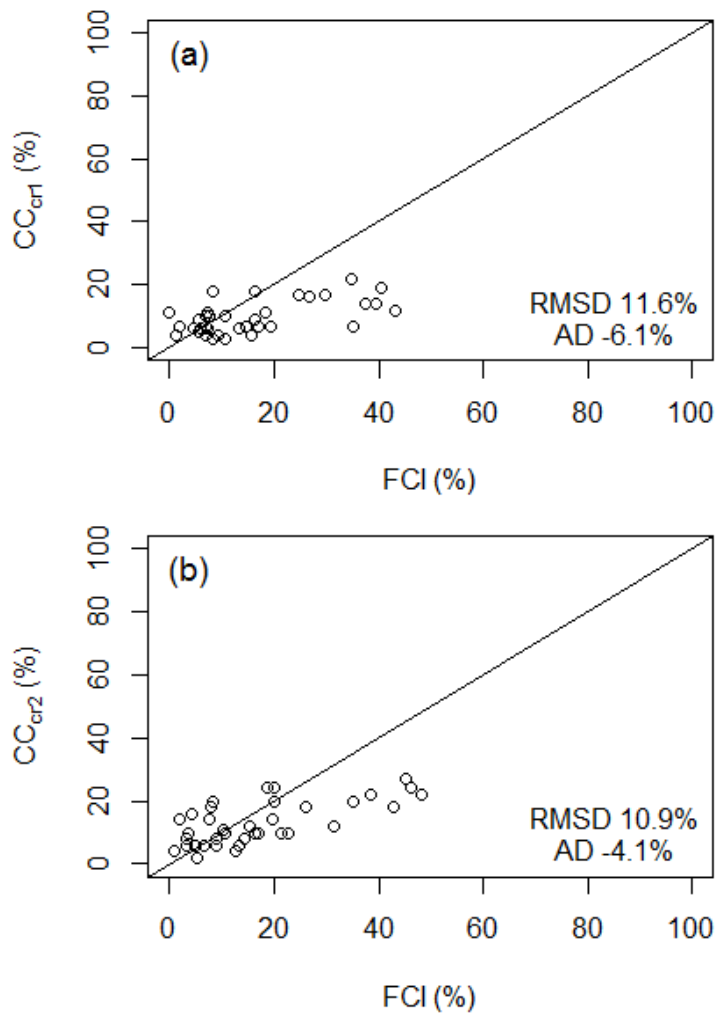

Figure 4. FCI against (a) $\mathrm{CC}_{\mathrm{cr} 1}(\mathrm{CBAF}=100)$ and $(\mathrm{b}) \mathrm{CC}_{\mathrm{cr} 2}$ $(\mathrm{CBAF}=200)$. Height threshold $=3 \mathrm{~m}$.
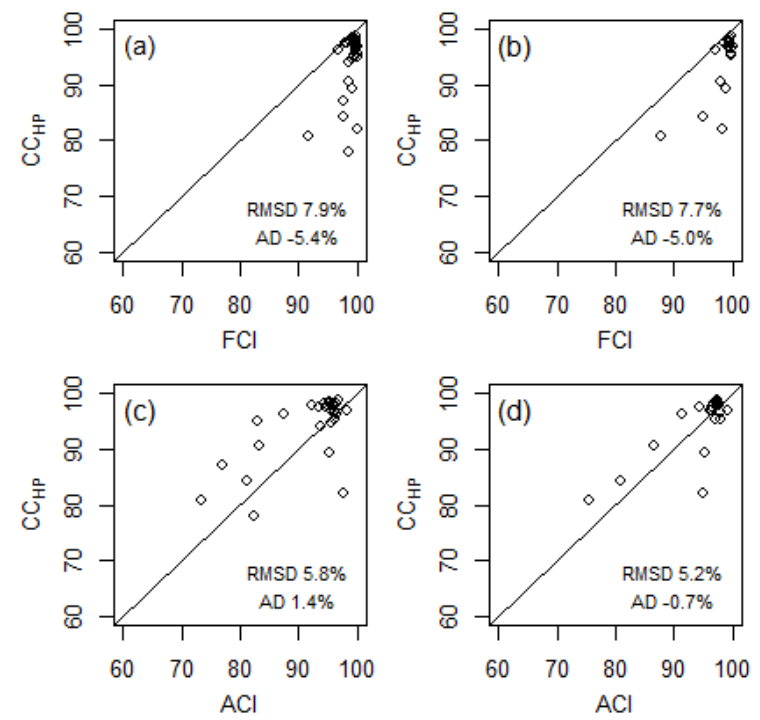

Figure. 5. Comparison of CCHP and (a) FCI from ALS1, (b) FCI from ALS3, (c) ACI from ALS1 and (d) ACI from ALS3.

Next, we compared $\mathrm{CC}_{\mathrm{HP}}$ and ALS cover indices. In contrast to the other field based $\mathrm{CC}$ estimates, $\mathrm{CC}_{\mathrm{HP}}$ were more closely related to ACI than FCI (Figure 5). As $\mathrm{CC}_{\mathrm{HP}}$ measurements were made in the indigenous forests and exotic plantations, $\mathrm{CC}_{\mathrm{HP}}$ was in general high. There was lots of variation in the lower range of the values, probably due to insufficient number of photo positions to estimate $\mathrm{CC}_{\mathrm{HP}}$ accurately in those plots. The larger $25 \mathrm{~m}$ plot radius and $3 \mathrm{~m}$ height threshold provided the best agreement.

Finally, we compared FCI and ACI in the overlapping plots of ALS1 and ALS3 scans using $3 \mathrm{~m}$ height threshold (Figure 6). Both indices showed good agreement across the complete range of FCI and ACI although FCI had somewhat smaller AD. Furthermore, in the plots with the greatest CC, ALS3 had larger values of ACI than ALS1.

\section{DISCUSSION}

Reliable CC maps would be useful for the land cover characterization of complex tropical landscapes. In this study, we compared several field and ALS based CC estimates across multiple tropical land cover types.

FCI based on single and first returns had good agreement with $\mathrm{CC}_{\text {Cajanus, }}$ which is often used as a reference method in the methodological comparisons (Korhonen et al., 2006; Stenberg et al., 2008). Good agreement between CC Cajanus and FCI is in line with the previous results from the boreal forests (Korhonen et al., 2011). As our data covered the complete range of CC and all the main land cover types and land uses, the results suggest that FCI provides a reliable mapping of $\mathrm{CC}$ for land cover characterization and forest area delineation also in the tropical areas. 

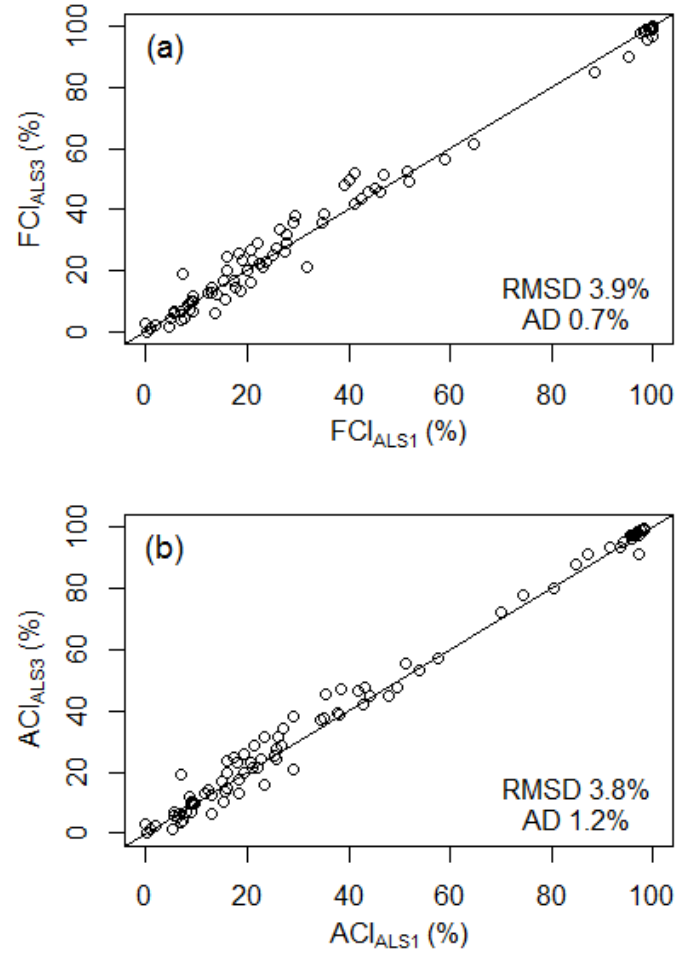

Figure 6. Comparison of (a) FCI and (b) ACI based on ALS1 and ALS3 data sets. Positive AD indicates that ALS1 shows on average smaller values.

The other field based methods showed more considerable average differences when compared to FCI. $\mathrm{CC}_{\text {trees }}$ provided rather good agreement with FCI in relatively when $\mathrm{CC}<20 \%$. However, $\mathrm{CC}_{\text {trees }}$ was smaller than FCI in the higher values. In the field inventory trees were included if $\mathrm{DBH} \geq 10 \mathrm{~cm}$. Therefore, the shrubs that had DBH $<10 \mathrm{~cm}$ and height greater than height threshold were included in ALS based CC but not in the field estimates. Furthermore, tree-like herbaceous plants, such as bananas, were not mapped in the field. This explains large differences in $\mathrm{CC}$ in some of the plots where bananas were abundant (i.e. large FCI but very small $\mathrm{CC}_{\text {trees}}$ ). Also, the best height threshold for $\mathrm{CC}_{\text {trees }}$ varied between the hills and the lowlands. The differing height-diameter relationship between the areas, and differences in the density of shrubs and small trees could affect the best height threshold.

Crown relascope has potential for the fast estimation of $\mathrm{CC}$ in the areas of low stem density, such as tropical woodlands and croplands, but the agreement with FCI was weak. In some of the plots, FCI was considerably higher, which is due to dense shrub cover in some of the plots similar to $\mathrm{CC}_{\text {trees }}$. Furthermore, because the radii to include trees were rather large because of large crowns (i.e. mean CD), it was difficult to see if crowns were overlapping in the denser plots. Therefore, larger CBAF could be considered in the future studies. It should also be noted that fixed and variable radius plots are not directly comparable, even if the radius is set separately for each plot based on the $\mathrm{CD}$.

We also demonstrated that $\mathrm{CC}_{\mathrm{HP}}$ has better agreement with $\mathrm{ACI}$, which considers all returns types. The same has been observed with GF and LAI in the boreal forests (Korhonen et al., 2011) and in this study area (Heiskanen et al., in press). In the dense forests, CC can be estimated accurately using relatively few photo positions (images) but more images are needed if $\mathrm{CC}$ is close to 50\% (Korhonen and Heikkinen, 2009). In our comparison, this was visible as greater scatter in the lower $\mathrm{CC}_{\mathrm{HP}}$ values.

In general, ALS cover indices that include also intermediate and last returns, such as ACI, are more sensitive to changes in scanning parameters than those using only single and first returns, such as FCI (Korhonen and Morsdorf, 2014). Although FCI can also change between different scanners, it should be fairly reliable as long as the scan angle is $<15^{\circ}$. In this study, the differences between indices were small in the overlapping area although although ALS1 and ALS3 were acquired with different sensors and from different flying heights. Some differences were observed in ACI in the closed forest stands (Heiskanen et al., in press).

In conclusion, the good agreement between FCI and $\mathrm{CC}_{\text {Cajanus }}$ highlights the potential of ALS for CC mapping in the tropical landscapes. ALS data provides CC estimates with unambiguous height definition. Hence, height based separation between trees and shrubs in the field should provide better correspondence between the field and ALS data than DBH based separation. Furthermore, it should be noted that tree-like herbaceous plants are included in ALS based indices and cause overestimation of $\mathrm{CC}$ when present.

\section{ACKNOWLEDGEMENTS}

This work was supported by the Ministry for Foreign Affairs of Finland under Building Biocarbon and Rural Development in West Africa (BIODEV) project. We also thank Taita Research Station of the University of Helsinki for the logistical support, and Jessica Broas and Darius Kimuzi for their contribution in the field work.

\section{REFERENCES}

Beckschäfer, P., Seidel, D., Kleinn, C., Xu, J., 2013. On the exposure of hemispherical photographs in forest. iForest $6, \mathrm{pp}$. 228-237.

Di Gregorio, A., 2005. Land cover classification system. Classification concepts and user manual. Software version 2. FAO, Rome.

FAO, 2010. Global forest resources assessment 2010. Main report. FAO Forestry Paper 163. FAO, Rome.

Gschwantner, T., Schadauer, K., Vidal, C., Lanz, A., Tomppo, E., di Cosmo, L., Robert, N., Englert Duursma, D., Lawrence, M., 2009. Common tree definitions for national forest inventories in Europe. Silva Fenn. 43(2), pp. 303-321.

Heiskanen, J., Korhonen, L., Hietanen, J., Pellikka, P. K. E., in press. Airborne LiDAR for estimating canopy gap fraction and leaf area index of tropical montane forests. Int J. Remote Sens.

Jennings, S. B., Brown, N. D., Sheil, D., 1999. Assessing forest canopies and understorey illumination: canopy closure, canopy cover and other measures. Forestry 72(1), pp. 59-74.

Jonckheere, I., Fleck, S., Nackaerts, K., Muys, B., Coppin, P., Weiss, M., Baret, F., 2004. Review of methods for in situ leaf area index determination: Part I. Theories, sensors and 
hemispherical photography. Agr. Forest Meteorol. 121(1-2), pp. 19-35.

Korhonen, L., Heikkinen, J. 2009. Automated analysis of in situ canopy images for the estimation of forest canopy cover. Forest Sci. 55(4), pp. 323-334.

Korhonen, L., Korhonen, K. T., Rautiainen, M., Stenberg, P., 2006. Estimation of forest canopy cover: a comparison of field measurement techniques. Silva Fenn. 40(4), pp. 577-588.

Korhonen, L., Korpela, I., Heiskanen, J., Maltamo, M., 2011. Airborne discrete-return LiDAR data in the estimation of vertical canopy cover, angular canopy closure and leaf area index. Remote Sens. Environ. 115(4), pp. 1065-1080.

Korhonen, L., Morsdorf, F., 2014. Estimation of canopy cover, gap fraction and leaf area index with airborne laser scanning. In: Forestry applications of airborne laser scanning, Springer, Dordrecht, pp. 397-417.

Morsdorf, F., Kötz, B., Meier, E., Itten, K. I., Allgöwer, B., 2006. Estimation of LAI and fractional cover from small footprint airborne laser scanning data based on gap fraction. Remote Sens. Environ. 104(1), pp. 50-61.

Nobis, M. Hunziker, U., 2005. Automatic thresholding for hemispherical canopy photographs based on edge detection. Agr. Forest Meteorol. 128(3-4), pp. 243-250.

Pellikka, P., Lötjönen, M., Siljander, M., Lens, L., 2009. Airborne remote sensing of spatiotemporal change (1955-2004) in indigenous and exotic forest cover in the Taita Hills, Kenya. Int. J. Appl. Earth Obs. 11(4), pp. 221-232.

Pellikka, P. K. E., Clark, B. J. F., Gonsamo Gosa, A., Himberg, N., Hurskainen, P., Maeda, E., Mwang'ombe, J., Omoro, L. M. A., Siljander, M., 2013. Agricultural Expansion and Its Consequences in the Taita Hills, Kenya. In: Kenya: a Natural Outlook, Elsevier, Amsterdam, pp. 165-179.

Schäfer, E., 2015. Tree species diversity estimation using airborne imaging spectroscopy. MSc thesis, University of Helsinki.

Solberg, S., Næsset, E., Hansen, K. H., Christiansen, E., 2006. Mapping defoliation during a severe insect attack on Scots pine using airborne laser scanning. Remote Sens. Environ. 102(3-4), pp. 364-376.

Stenberg, P., Korhonen, L., Rautiainen, M., 2008. A relascope for measuring canopy cover. Can J. For. Res. 38(9), pp. 25452550 .

Zomer, R. J., Trabucco, A., Coe, R., Place, F., 2009. Trees on farm: analysis of global extent and geographical patterns of agroforestry. ICRAF Working Paper 89. World Agroforestry Centre, Nairobi, Kenya. 